\title{
Applied Research of Solidified Soil Characteristic Test on Water Conservancy Project
}

\author{
Ouyang Yong
}

Nanchang Key Laboratory of material and structure detection Jiangxi University of Technology

Keywords: Soil curing technology; Experimental investigation; Anti-seepage reinforcement; Curing effect; Compressive strength; Technical application

\begin{abstract}
The curing technology of soil has received growing concern in civil engineering. Therefore, researches of its characteristics have academic significance and practical worthiness. The application in water conservancy project has obvious effects on resources saving, flood prevention, danger elimination, water-efficient irrigation, and effective use of groundwater resources has a broader and promising future. This paper firstly researches on the characteristic of soil curing as well as soil. Based on this, it carries out indoor comparative tests and verification on the characteristics of several common soil solidifications so as to explore the influence of different classifications, types, incorporations, ages and curing conditions for samples on the testing results. Besides, it also expects to explore the different curing effects caused by soil with different characteristics. In field test, this paper combines both middle-size and small-size reservoir reinforcement engineering, introduces soil curing technology to carry out field test and the application experiment proves that the addition of soil curing can help to improve the impermeable and compressive strength. In addition, it also has advantages such as convenient construction, indigenous raw materials usage, friendly maintenance etc which has significant application value.
\end{abstract}

\section{Introduction}

From traditional cement, lime curing application to new solidified soil application the soil curing technology has always been the most promising research in Subject of Civil Engineering. Along with continuous researches on various soil curing agents, the solidified soil materials have become a multidisciplinary and comprehensive subject. Currently, foreign countries have already had mature technology in terms of soil curing application, which is widely used in transportation. In 1980s, this technology was introduced into China which has been improved based on Chinese characteristics. However, because of various reasons, applied researches on water conservancy engineering are not mature and systematical therefore, it is necessary to carry out applied researches of dam soil curing technology.

In early 20th century, due to the construction of roads, ports, airports and other projects some developed economies started to adopt lime and water to improve the soil quality with good results. In the long-term soil stabilization projects, people gradually realized that adopting traditional soil curing materials such as lime, cement and fly ash have obvious shortcomings, which fails to meet construction needs.

Soil curing agents, namely the soil solidification materials can be directly attached to soil particle as well as clay mineral to form cementitious material. In many cases, the mechanical properties of 
the soil does not depend on the strength of basic structural unit but the adhesive force which enables disperse soil particles to contact with each other to improve the bonding force. Other approaches can be adopted to solidify soil but in general there are three ways. Firstly, impose greater pressure to make it rock; secondly, high temperature melt; thirdly, normal temperature cure. At present, in common normal temperature cures, calcareous soil, soil cement, asphalt, resin strengthening soil, chemical, electro-osmotic and electrochemical methods are often adopted with special features as well as proper ranges and conditions.

This paper pays attention to the test research on soil curing so as to obtain test data and conclusions based on different curing effects caused by different types as well as mixture amounts of curing agent which can be research references. In addition, it combines dam strengthening technique and adds an amount of curing agent in earth filling, solidifying slurry and grass-planting brick to test the curing effect. Based on this, this paper sums up the advantages of curing agents usage as well as existing problems.

By researching on the curing mechanism of soil solidification, it elaborates the features of ions, acrylates, cement base, lime base etc. What's more, it also lists typical test for each category to explain its application scope and condition. By comparing the features of several common soil solidifications, this paper aims to research on different service conditions of each category.

Concerning the soil curing behavior, common soils are clayey soil, cohesionless soil, miry soil, special soil, abandoned dregs, and industrial ash residue. This paper aims to study their physicochemical property, engineering properties and classifications to carry out different experimental studies on stabilization based on their characteristics, mineral as well as chemical compositions.

Based on the compounding ratio of soil material and preparation of samples, it expects to improve the test methods and obtain concrete testing results to analyze various test results and compare the differences between measured value in laboratory experiment and in-situ test and explain the reason for the differences.

What's more, it analyzes and sums up the research results, aiming to put forward rational proposals to predict the research prospect and contrapuntally suggest issues remaining to be solved. Meanwhile, this paper also carries out qualitative comparison on the performance of solidifying materials so as to indicate problems and obstacles exist in the course of using and promoting this technology.

\section{Study on soil characteristics}

Common methods of soil solidification are machinery and chemical curing. For example sandy material can be cured by cement while fire clay and plastic material can be cured by lime, which are chemical curing methods. Common soil curing technology directly connects the soil particle surface or reacts with soil mineral composition to create cementitious material to strengthen binding power and achieve consolidation. The soil solidification has a wide range of application with stable performance, low cast and convenient construction condition which is suitable for domestic market. Soil solidification can be adopted in the roadways \& bridges, environmental engineering and water conservancy project, which is widely used in reinforcement, slope protection, anti-seepage and flood prevention with significant effect in flood prevention, danger elimination, soil and water conservation, and water-efficient irrigation. 
Curing agent is a new building material properly mixed up by high-early strength cement, silicate cement and active admixture (slag and fly ash etc) based on the strength. Because of different categories, it has main components such as silicate cement and high-early strength cement, activator, and water-binding agent. Therefore, when it is mixed up with soil, it ignites a series of chemical reactions, a glittering array of acicular crystals are created crossing soil particle to form intensified skeleton. What's more, silicate hydrates are filled in the skeleton so as to intensify the curing system. Finally, based on the powerful stimulation caused by the various activators, mixed material and part of soil particles also participate in the chemical reaction so as to ignite effective curing effect with good strength.

At present, there are many types of soil solidifications with different solidification principle, which can be divided into 3 categories based on the curing mechanism:

Firstly, the electric curing is a hot concentrated solution. It is made up of pyrolysis of a petroleum product and sulfonated bodies, which belongs to liquid. After being dissolved in the water, it becomes an ion exchange mediator. What's more, after being applied to the earth, it carries out ionization exchange with soil colloid to change the water molecule and ionizer characteristics, damage the structure of capillary of soil pore and finally the soil changes from hydrophilia to water repellency.

Secondly, biological enzyme curing agent is made up of the consolidated soil secreted out by animals. It is fermented from organic matter, which belongs to protein enzyme in liquid position. After being melted into the water by a certain percentage, it can help to strengthen the adhesiveness of soil particles based on biological enzyme catalyst and pressing to finally form impermeable structure.

Hydration curing agent is a kind of solid powder substance processed with limestone, iron, clay, gypsum, fly ash. Soil curing agent is put into the soil to interact with water and create gelatination so as to drive out the water and form module with compressive and impervious strength. This curing agent can be divided into various types such as cement base curing agent and lime base curing agent etc.

\section{Study on the characteristics of common soils}

Soil, as the most widely used building material or media in civil engineering can be regarded as the object of curing technology. Because of its variety and complexity, the selection is varied. Soli curing agents can be adopted in various soils with different effects. Therefore, the soil curing technique is inevitably related to the characteristics of various soils. This paper aims to research on the characteristics of curing agents on the selection, mixture amount, curing conditions etc.

Soil refers to the particle formed based on clastation with a great disparity in terms of size. After various move types, they become weakly caking deposited matters or matters with no bond in the natural environment. Soil can be regenerated into rock (sedimentary rocks) via compression consolidation and cementation as well as curing. During the long geologic time, due to a variety of internal force and exogenic geological process, a dazzling array of rocks and dirt can be formed. What's more, bedrocks will regenerate into various mulching soils through weathering, erosion, transportation, deposition etc.

Cohesionless soil refers to sand soil as well as gravel soil and the main state indicator is the degree of compactness. The sand soil can be evaluated by the size of natural pore, which can be seen 
in the table 1 . The common pore size e, relative density $D_{r}$, standard penetration test $\mathrm{N}$ can be regarded as the standards to determine the degree of compactness. For those large soils with a large amount of gravel soils, it is hard to carry out indoor test or penetration test to know the degree of compactness. Therefore, we can adopt outdoor identification methods to know the degree of compactness based on its skeleton granule contents and drillability etc.

Table 1 Divide the degree of compactness based on the volume of e

\begin{tabular}{|l|l|l|l|l|}
\hline Title of soil & Dense & Medium-dense & Slightly-dense & Loose \\
\hline $\begin{array}{l}\text { Gravelly sand, coarse sand, } \\
\text { medium sand }\end{array}$ & e $\langle 0.60$ & $0.60 \leq \mathrm{e} \leq 0.75$ & $0.75 \leq \mathrm{e} \leq 0.85$ & $\mathrm{e}\rangle 0.85$ \\
\hline Fine sand, Fine sand & $\mathrm{e}\langle 0.70$ & $0.70 \leq \mathrm{e} \leq 0.85$ & $0.85 \leq \mathrm{e} \leq 0.95$ & $\mathrm{e}\rangle 0.95$ \\
\hline
\end{tabular}

With the increasing of water content in clayey soil, the condition of soil changes from solidity to semi-solid state to plastic state and to liquid. What's more, relevant bearing capacity decreases. The compactness is reflected by the relative consistency (soft and hard stability) which embodies the associative strength and is changed along with the water amount. By the way, the boundary water content of different conditions has significant meaning.

\section{The applied research of solidified soil on water conservancy project}

Soil curing agents are new chemical materials applied in civil engineering, which can be widely adopted in water conservancy project, and possess unique effects in terms of solidifying soil. Curing agents have good strength and impervious ability which can solve the problems of cement in soil solidification. What's more, soil curing agents can be applied in slope protection of rivers and lakes, reservoir and dam reinforcement, transmission works, soft foundation treatment, microorganism sludge solidification concretes repair, temporarily road, reclaim land from the sea as well as environment protection project. After the soil solidification being formed, it is compressive, impervious, frost-resisting, flexural strength with advantages such as low cost, convenient construction condition and elegant appearance.

In order to meet the requirement of manufacturing, China began to introduce and develop a dozen of new techniques for dykes and dam leakage proof and reinforcement since its founding especially after 1980, and some techniques are independent, and have reached international advanced level. At present, new techniques for anti-seepage reinforcement include: comprehensive technical management for dangerous dam, mould vibro-sinking of impervious panel walls, split curtain grouting technique, technique of jet grouting impervious wall, impervious earth membrane, grade ingredients grouting technology, technique of concrete seepage-proof wall etc, among which stabilizers for grouting materials and wall materials are widely used and promoted. The main functions for material stabilizer plus include: firstly, improve the rheological properties of mixtures to help them be suitable for mixing, transferring, pouring and vibrating etc; secondly, adjust setting time and hardening ability; thirdly, guarantee and improve various mechanical properties of the coagulation body such as compressive strength, bending strength, tensile strength, modulus of elasticity, impermeability, frost resistance performance etc; fourthly, improve the durability; fifthly, compensate the demerits of plain concrete such as its swelling shrinkage strength; sixthly, improve the special requirement of new materials such as high-strength, plasticity, self-leveling, zero defects, 
leakage prevention, waterproof, anti-corrosion etc; seventhly, save gelatinization materials and reduce the construction cost; eighthly, other special needs.

HEC is mainly adopted in impermeable lining project, temporary highway engineering for lakes and the sea in terms of blood-prevention, foundation engineering for lakes and seas, road engineering and slope protection works etc. This test tries to apply it into the technique of split grouting so as to test its curing strength as well as anti seepage performance, aiming to promote its application.

In dam grouting, proper selection of mud is an important premise to guarantee the quality because different serums will directly affect the rate of consolidation and the seepage control effect. Therefore, before grouting we have to test the physical and mechanical properties so as to have a good knowledge and choose proper mud in the grouting implementation. The test contents include liquidity (viscosity), sweating rate, and stability etc. What's more, the requirements include: good grouting ability, stability and quick dehydration ability so as to form powerful impermeable strength and the deformation modulus shall be close to dam soil. Proper addition of soil curing agents can help to change these performances. In this test, I added 10\% HEC high strength and water stability earth consolidator. After the completion of about 1 month, I studied the formation and tested the degree of consolidation and permeability. I find out that the compressive strength is improved by $10 \%$ and the permeability indicator decreases the magnitude which can improve the slurry properties of grouting material.

\section{Conclusions}

On the basis of serious investigation and extensive researches, it analyzes the properties of soil solidified agent and carries out external test, conducts field test as well as application, combining real water conservancy project to acquire useful test data and results. It lays a solid foundation for the further research and development of soil curing technology. The following conclusions can be concluded:

Firstly, soil curing agents, firstly adopted in expressway can also be used in the hydraulic engineering. Adopting soil curing agents, we can carry out construction of seepage control and reinforcement for small reservoir and its strength and seepage effects have been improved. If the implementation quality is assured, the infiltration amount shall be greatly decreased after the reinforcement. In addition, application effect in terms of hasty road as well as slope protection shall be more understanding.

Secondly, its compatibility is good, which is convenient to combine with various construction methods. For example, in the stabilization for seepage control of earth dam, proper rate can be added in the filling or solidifying slurry so as to greatly improve the curing effect without adding much to costs.

Thirdly, the compound and construction technology of soil curing agents shall be key sectors to guarantee the quality. We have to adopt professional equipments and invite experienced workers to carefully carry out the implementation, and seriously check to ensure the construction quality or the field test shall be greatly different from the laboratory results.

Fourthly, the current survey results for strengthening flood prevention road and dam top are good. Yet, the strength and durability remain to be checked.

Fifthly, soil curing agents have a wide application range. Adding relevant curing agents to solidified soil and grouting will lead to a condition that the strength and impervious performance are significantly improved with a relatively low cost. What's more, it has better performance comparing 
to cement and lime. Moreover, while comparing to concrete, soil curing agents can help to reduce the amount of a dazzling array of cement and sand stone. As a result, its comprehensive cost is favorable.

\section{Acknowledgment}

This work was supported by Project on professional and characteristical construction of Jiangxi province 2010 (Civil Engineering) and Project on the planning and construction of disciplines in Jiangxi University of Technology (Structure Engineering)

\section{References}

[1] Zhao Y, Kong L, Guo A, et al. Mechanical behaviors and water-sensitive properties of intact Guangxi laterite[J]. ROCK AND SOIL MECHANICS-WUHAN-, 2003, 24(4; ISSU 85): 568-572.

[2] Cao Y H, Yan S, Zhao L. Engineering properties and microstructure feature of solidified sludge[J]. Yantu Lixue (Rock and Soil Mechanics), 2006, 27(5): 740-744.

[3] SHANG J, LIU J, ZHAO X. Test study on construction performance of energy-saving material [J]. Journal of Xi'an University of Architecture \&technology, 2003, 4:005.

[4] Longlei D, Guirong Y A N, Hongjian L. The dynamic centrifuge model test in geotechnical engineering [J]. Chinese Journal of Rock Mechanics and Engineering, 2000, 19(6): 789-793.

[5] Rui D. Experimental study of the surface reactions between clay minerals and water glass [J]. CHINESE JOUNAL OF GEOTECHNICAL ENGINEERING, 1999, 3.

[6] Hua H. The influencing characteristics and mechanism of water content on rheological parameters of soft-soil[J]. Geotechnical Engineering Technique, 2005, 19(3): 134-136.

[7] ZHU Z, LIU S, XUN H. Study of stabilized silt in Xu-Su area [J]. Rock and Soil Mechanics, 2004: 07.

[8] WANG H, GU C, Su H. Study of the Sedimentation of the Qianiang River's Hydraulic Fill [J]. Journal of Lianyungang Technical College, 2002, 2.

[9] Paria S, Yuet P K. Solidification-stabilization of organic and inorganic contaminants using portland cement: a literature review[J]. Environmental Reviews, 2006, 14(4): 217-255.

[10] Jin X R, Yu J L, Gong X N, et al. Field tests on soft soil with confined underground water by vacuum-surcharge preloading [J]. Chinese Journal of Geotechnical Engineering, 2007, 5: 027. 